pink to deep red Howers contrasting sharply with the ungainly naked branches which bore them.

We soon saw the very fresh prints of Elephant in the rain puddles along the path, and then suddenly we saw a huge grey bulk peering at us through the trees some fifty yards away. He stared for several minutes and stood facing us with his great ears quivering in alarm and annoyance. 'Then he crashed off through the bush following the rain-storm.

All the way to Afmadu we came upon herds of Gerenuk, Grant's Gazelle and parties of Wart-Hog in profusion; the latter splashing about in the mud. Then we saw a beautiful Black-backed Jackal ruming across our front with some heavy dark object in its mouth. This creature showed up clearly in the half-light with its striking blue-black saddle against rufous limbs. As we drew nearer we saw that the object in its mouth was a Vulturine Guineafowl, plundered from some nearby flock.

It was getting dark as we ploughed our way through the last few miles of water, churned-up mud, and a milling mass of bellowing cattle, to arrive safely once again in Afmadu.

\title{
AUSTRALIAN FAUNA CONFERENCE
}

An Official Report has reached us on a Conference of Authorities on Australian Fauna and Flora held at Hobart, Tasmania, from 7 th to 9th December, 1949. This conference was convened by the Animals and Birds Protection Board of Tasmania, a member of our Society. All States except Queensland were represented.

The Conference was opened by the Attorney-General, Mr. Fagan. The Chair for the first morning was occupied by the Hon. J. J. Dwyer, Minister for Agriculture and Chairman of the Animals and Birds Protection Board, but was then taken over by Dr. J. Pearson, Director of the Tasmanian Museum.

Wild Live Conservation in Australia is entirely the responsibility of the various states, not the Commonwealth Government. The Wild Life Section of the Commonwealth organization C.S.I.R.O. (Commonwealth Scientific and Industrial Research Organization) is for the present entirely concerned with the control of the rabbit.

The following facts emerged about kangaroos, the damage they do, and their protection.

In Queensland kangaroos receive no protection. In New 
South Wales they are protected although in some areas in the far west they are looked upon as a menace. There is, however, no general open season but open seasons for particular times and areas are declared. Permits to land owners to destroy on their land a certain number of kangaroos are also given when considered necessary.

In Victoria kangaroos are getting scarce in populated areas, that is in a large portion of the state, but are still common in the far north-east and far north-west. Sometimes they, especially the Great Grey Kangaroos, do damage by getting into young crops and thrashing their tails about. There is no open season but when, after investigation, complaints have been proved to be justified, permits to destroy kangaroos are given without hesitation.

The method of investigation is as follows. The property owner making the complaint is interviewed and the property inspected for evidence of kangaroos, such as droppings or foot and tail marks. Where properties are situated on the verges of forests kangaroos lie up by day and come out at night or in the early morning. The investigators watch at the appropriate time, properly concealed, and are able to build up a fair estimate of the damage actually occurring.

In the majority of cases the damage is grossly exaggerated. Sometimes where large mobs of kangaroos are reported, the investigators have not only failed to see a single kangaroo but have found no sign of any having been there. When the price of skins is high the complaints of damage increase enormously. If the investigations were not properly carried out, kangaroos would disappear entirely, at least from the more populated areas of Victoria.

In Victoria generally kangaroos are becoming scarcer and stronger protection measures may be necessary. It is thought that much of the damage attributed to kangaroos may in fact be caused by other animals such as rabbits, and it has been proposed that experimental areas be set up stocked with kangaroos. Some of these areas would be used to test the amount of pasture consumed, others the amount of damage done to crops.

In South Australia kangaroos are protected from October to March, their breeding period, but where they are very prevalent this protection has been removed and they can be destroyed at any time. About seventy thousand skins are exported annually, mostly to U.S.A. for car upholstery. The system for investigation of complaints of damage by kangaroos is much the same as in New South Wales and Victoria. 
In Western Australia Grey Kangaroos are strictly preserved in practically the whole of the South-Western Land Division, but no other protection is given to kangaroos.

The fauna of Tasmania is being maintained at a fairly good level. The Platypus has been saved by total protection. The Thylacine is on the verge of extinction although the reward which used to be paid for its destruction has been stopped and there are still thousands of square miles of suitable country for this animal. The reason for its rapid diminution is obscure.

Everywhere the Koala is entirely protected and owing to the great efforts made on its behalf seems on the whole to be increasing. Many colonies have been discovered in New South Wales, one of which has nearly 1,000 animals. Man-made bush fires constitute one of its most serious menaces, though people still cut down trees with koalas in them and take the young.

Breeding of Koalas for release in sanctuaries has been carried out at Taronga Park and elsewhere and it has been found that the correct breeding proportion is about six females to one male.

It seems that the Commonwealth Government has introduced goats on to Macquarie Island, a great bird sanctuary, and that they have already made great inroads into the vegetation. It was suggested at the Conference that a protest should be made and the Commonwealth Government requested that the matter should be reconsidered.

\section{PROTECTION OF WILD LIFE IN NEW SOUTH WALES}

In 1948, by Act of Parliament, New South Wales established a Fauna Protection Panel for the care and protection of her native fauna. The Panel consists of 14 members including the Chairman, Mr. F. J. Griffiths, who has the title of Chief Guardian of Fauna. The Deputy Chairman is Mr. E. J. Hallstrom, President of the Taronga Zoological Park Trust. 'The Sydney University is represented by its Professor of Zoology. There is one member representing rural interests. The Linnean Society and Royal Zoological Society are represented. The Wild Life Protection Society of Australia is represented by its Honorary Secretary, Mr. A. A. Strom.

The duties of the Panel are laid down in the Act. Besides the formal one of advice to the Minister, they include educational activities to awaken appreciation of the value of wild life, the 